\title{
Perfil escolar de estudantes com deficiência na Educação de Jovens e Adultos, nível ensino médio
}

School profile of students with disabilities in Youth and Adult Education at the high school

Perfil escolar de estudiantes con discapacidad en la educación de jóvenes y adultos nivel de enseñanza media

\section{* Graciliana Garcia Leite}

Mestranda na Universidade Federal de São Carlos (UFSCar), São Carlos, São Paulo, Brasil. gracilianagl@gmail.com

\section{** Juliane Aparecida de Paula Perez Campos}

Professora doutora da Universidade Federal de São Carlos (UFSCar), São Carlos, São Paulo, Brasil. jappcampos@gmail.com

Recebido: 27 de junho de 2017

Aprovado: 10 de dezembro de 2018

\section{RESUMO}

O objetivo do estudo foi analisar o perfil escolar de estudantes com deficiência matriculados na Educação de Jovens e Adultos (EJA), nível ensino médio. O estudo contou com a participação de 10 estudantes de diferentes escolas estaduais de três municípios do interior do estado de São Paulo. Para a coleta de dados, aplicou-se o questionário socioeconômico adaptado do Exame Nacional para Certificação de Competências de Jovens e Adultos (ENCEJA 2013). Os resultados indicaram perfil jovem dos estudantes, predominância do sexo masculino, baixo nível de escolaridade dos pais, perfil econômico baixo e fragmentação do processo de escolarização, caracterizado pela interrupção dos estudos. Foi possível concluir que os estudantes reconhecem que com o retorno à escola eles têm a oportunidade de ascender profissionalmente e de romper com o processo de fragmentação escolar. Destacamos a relevância do estudo porque, com o conhecimento do perfil dos estudantes que frequentam a EJA, suas características e trajetória escolar, damos-Ihes as condições de desenvolvimento educacional no contexto do ensino regular. Palavras-chave: Educação especial; Educação de Jovens e Adultos (EJA); Ensino médio.

\section{ABSTRACT}

The objective of the study was to analyze the schooler profile of students with disabilities enrolled in the Education for Young People and Adults (EJA) at the high school. The study was attended by 10 students from different state schools of three municipalities in the interior of the state of São Paulo, Brazil. For data collection, the socioeconomic questionnaire adapted from the National Exam for the Certification of Skills of Young and Adults (ENCEJA 
2013) was applied. The results indicated a young profile, male sex predominance, low parents schooling, low economic level and fragmentation of the schooling process, characterized by the interruption of studies. It was possible to conclude that students recognize that the return to school represents the opportunity professional ascension, breaking with the process of school fragmentation. We emphasize the relevance of the study, since it is necessary to know the profile of the students who attend the EJA, as a way to understand their characterization and school trajectory, enabling the educational development of these students in the context of regular school.

Keywords: Special education; Youth and Adult Education (EJA); High school.

\section{RESUMEN}

El objetivo del estudio fue analizar el perfil escolar de estudiantes con discapacidad matriculados en la Educación de Jóvenes y Adultos (EJA), nivel escolar medio. El estudio contó con la participación de 10 estudiantes de diferentes escuelas estatales de tres municipios del interior del estado de São Paulo. Para la recolección de datos, se aplicó el cuestionario socioeconómico adaptado del Examen Nacional para Certificación de Competencias de Jóvenes y Adultos (ENCEJA 2013). Los resultados indicaron perfil joven de los estudiantes, predominio del sexo masculino, bajo nivel escolar de los padres, perfil económico bajo y fragmentación del proceso de escolarización, caracterizado por la interrupción de los estudios. Es posible concluir que los estudiantes reconocen que el retorno a la escuela representa la oportunidad ascendente profesional, rompiendo con el proceso de fragmentación escolar. Destacamos la relevancia del estudio, pues es necesario conocer el perfil de los estudiantes que frecuentan la EJA, como forma de comprender su caracterización y trayectoria escolar, oportunizando el desarrollo educativo de estos sujetos en el contexto de la enseñanza regular.

Palabras clave: Educación especial; Educación de Jóvenes y Adultos (EJA); Enseñanza media.

\section{Introdução}

O debate em torno da Educação de Jovens e de Adultos (EJA) no Brasil vem de longo tempo e, dado o interesse de toda a sociedade, aos poucos passou a ser um problema assumido pelos poderes governamentais. Mesmo com o reconhecimento dos direitos adquiridos no processo da democratização no país, no final da década de 1980 , e os compromissos estabelecidos em fóruns internacionais, observa-se que 0 avanço das políticas afins à questão não possibilitou o alcance das metas propostas (HADDAD; DI PIERRO, 2015).

Como reflexo dessa situação, evidencia-se o elevado número de analfabetos no país - os dados divulgados pelo IBGE (2014) indicam que, em 2013, havia mais de 13 milhões 
http://dx.doi.org/10.5902/1984686Xx27878

de pessoas analfabetas com 15 anos ou mais, aproximadamente $8,5 \%$ da população, em 2004 o índice era de 11,5\%.

Acrescenta-se ao desafio da alfabetização o processo de inclusão dos estudantes Público-Alvo da Educação Especial (PAEE), por se tratar de um alunado que apresenta especificidades e possui tanto o direito ao acesso como à permanência na escola comum. Nesse sentido, as discussões sobre a educação especial têm ganhado força com a inclusão desses estudantes nas classes regulares do ensino, compromisso firmado pelo governo em diversos documentos e acordos internacionais.

A EJA é uma modalidade prevista na LDBN 9394/96 - Lei de Diretrizes e Bases da Educação Nacional, destinada àqueles que não obtiveram acesso na idade regular ao ensino. A idade para ingresso na modalidade é de 15 anos completos para o ensino fundamental e 18 anos completos para o ensino médio (BRASIL, 2010). Cabe destacar que os estudantes que chegam à EJA geralmente já vivenciaram experiências educativas nem sempre bem-sucedidas, mesmo assim eles buscam na escola um espaço para ascensão no trabalho e estudo.

A Política Nacional de Educação Especial na perspectiva da Educação Inclusiva (BRASIL, 2008) foi determinante para garantir o acesso aos estudantes PAEE nas escolas regulares, o que fez despertar novas concepções da educação especial nos sistemas de ensino. No que tange à EJA, a Política Nacional de Educação Especial reconhece que “(...) as ações da educação especial possibilitam a ampliação de oportunidades de escolarização, formação para a inserção no mundo do trabalho e efetiva participação social” (BRASIL, 2008, p.16).

Sobre tal assunto, Haas (2013) destaca que as modalidades educacionais, EJA e Educação Especial, experimentam um momento de reformulação de suas políticas, sob a responsabilidade pública do Estado, refletindo no contexto escolar a aproximação dessas modalidades educacionais pelo crescente ingresso de jovens e adultos com deficiência nos bancos escolares.

Em relação à demanda desses alunados, Hass (2015) assinala que tanto os estudantes com deficiência, como os jovens e adultos, em processo de escolarização apresentam as mesmas necessidades:

(...) serem reconhecidos além de suas carências, além de uma visibilidade dada por suas vulnerabilidades ou pela negação de sua condição como sujeitos históricos. Embora o caráter de suplência não seja mais a tônica das políticas públicas, este ainda sobrevive no imaginário social e nas práticas pedagógicas (HASS, 2015, p.349). 
http://dx.doi.org/10.5902/1984686Xx27878

Ainda Haas (2015) enfatiza que os indivíduos com deficiência matriculados na EJA geralmente têm passagem de permanência significativa em Instituições de Educação Especial ou Classe Especial e, ainda, de fracasso na turma regular. Haas (2015, p. 349) observa que “(...) pensar uma política pública para a EJA requer compreender essa identidade coletiva, refletindo sobre políticas afirmativas para esse coletivo de sujeitos, historicamente negado, como fundamento e identidade da EJA".

Considerando a EJA nível ensino médio, as matrículas aumentaram nos últimos anos, porém ainda não retratam a universalização, pois, quando se compara o número de estudantes com deficiência no ensino fundamental, é possível constatar um número superior ao das matrículas no ensino médio (MOREIRA; CARVALHO, 2014). As autoras concluem que é grande o número de alunos com deficiência que não conseguem frequentar a última etapa da educação básica, mesmo com o direito garantido constitucionalmente.

Ao analisar as matrículas dos alunos com deficiência no estado de São Paulo, e especficamente no município de Campinas, entre os anos de 2007 a 2012, Laplane (2014) apurou uma maior concentração de matrículas nos primeiros anos do ensino fundamental, fazendo pensar que muitos desses estudantes não conseguem avançar para as etapas posteriores do ensino. Nesse aspecto, Laplane (2014, p. 202) afirma que, embora tenha ocorrido o aumento do número de alunos atendidos, "(...) a distribuição dos alunos entre os níveis de ensino expõe um quadro que, ainda, prima pela desigualdade".

Quanto à escolarização de estudantes com deficiência intelectual na EJA, Fantacini e Campos (2017) realizaram um estudo com o objetivo de identificar e analisar os motivos que levaram os alunos com deficiência intelectual a se matricular na EJA e quais os fatores que os levaram a concluir ou desistir dos estudos nessa modalidade de ensino. As autoras verificaram que poucos estudantes conseguiram finalizar os estudos na EJA; os principais fatores que dificultaram e/ou impediram a conclusão estavam relacionados às dificuldades pessoais e do contexto escolar como: retenções; necessidades de trabalhar; dificuldade em conciliar o horário; falta de apoio pedagógico, falta de interesse da escola; falta de pessoas capacitadas. Todos esses fatores fizeram com que muitos estudantes retornassem para a Escola Especial. Entre os motivos para a permanência foram identificados: a presença nas aulas (assiduidade); incentivo da família, professores e gestores; aquisição de novos conhecimentos e novas amizades.

Assim, podemos reafirmar que tanto a EJA quanto a Educação Especial visam à escolarização das pessoas, de modo específico incluindo os estudantes com deficiência 
http://dx.doi.org/10.5902/1984686Xx27878

que não puderam continuar os estudos na idade regular, sem ignorar, todavia, que os desafios ainda são muitos quando se trata de proporcionar uma educação inclusiva e de qualidade para tal segmento.

A EJA, nos últimos anos, passou por uma reconfiguração ao abranger estudantes com perfis e características variadas, marcados por experiências escolares nem sempre bemsucedidas. De certo modo, todos os estudantes, com suas trajetórias únicas, procuram na escolarização um caminho capaz de nortear sua vida e integrá-los no trabalho e na sociedade. Dessa forma, saber quem são e como se comportam os estudantes que frequentam a EJA em seu processo de escolarização fornece elementos para repensar a inclusão escolar, pois o acompanhamento de suas vivências reais abre um mundo de novas percepções.

Diante deste contexto apresentado, o presente estudo, tem como objetivo caracterizar o perfil e trajetória escolar dos estudantes com deficiência, matriculados na educação de jovens e adultos, nível ensino médio.

\section{Método}

Participaram do estudo 10 estudantes do sexo masculino que apresentam deficiências variadas. A idade dos participantes variou entre 19 anos e 33 anos; destes, cinco estudantes estavam no $2^{\circ}$ ano do ensino médio e outros cinco no $3^{\circ}$ ano do ensino médio.

Para a realização da pesquisa foram adotados como critérios de participação: a) Ter algum tipo de deficiência; b) Autodeclarar-se deficiente; c) Estar matriculado e frequentando a EJA, nível ensino médio na rede estadual; d) Concordar em participar do estudo e assinar o termo de consentimento livre e esclarecido, ou termo de assentimento no caso do participante com deficiência intelectual.

A pesquisa foi realizada nas dependências de oito escolas estaduais, pertencentes a três diretorias de ensino do interior do estado de São Paulo, conforme quadro a seguir:

\begin{tabular}{|c|c|c|c|}
\hline \multicolumn{4}{|c|}{ Quadro 1 - Distribuição das escolas participantes } \\
\hline Diretoria de Ensino & Município & Escola & Participante \\
\hline 1 & Matão & $1 \mathrm{~A}$ & Gustavo \\
\hline 2 & Batatais & $2 \mathrm{~A}$ & Jean; Luciano \\
\hline & Luiz Antônio & $2 \mathrm{~B}$ & Dênis \\
\cline { 2 - 4 } & Ribeirão Preto & $2 \mathrm{C}$ & José \\
\hline \multirow{4}{*}{3} & Ibaté & $3 \mathrm{~A}$ & Cleiton \\
\cline { 2 - 4 } & São Carlos & $3 \mathrm{~B}$ & Igor; Wesley \\
\cline { 2 - 4 } & & $3 \mathrm{C}$ & Luan \\
\cline { 3 - 4 } & & $3 \mathrm{D}$ & Danilo \\
\hline
\end{tabular}

Fonte: As autoras (2016). 
Antes da coleta de dados, o projeto de pesquisa foi encaminhado para o Comitê de Ética em Pesquisa em Seres Humanos da Universidade Federal de São Carlos, o qual atendeu às exigências com o Certificado de Apresentação para Apreciação Ética (CAAE) no 49256515.0.0000.5504. Todos os participantes assinaram o termo de consentimento livre esclarecido, e o participante com deficiência intelectual assinou o termo de assentimento. As entrevistas foram gravadas com permissão dos participantes, depois transcritas na íntegra.

Como instrumento para a coleta de dados, utilizou-se o Questionário Socioeconômico do Exame Nacional para Certificação de Competências de Jovens e Adultos (ENCEJA 2013) adaptado pelas autoras, que contemplava perguntas fechadas, divididas em três temas: a) perfil dos participantes; b) caracterização socioeconômica do núcleo familiar dos participantes; c) informações gerais relacionadas à trajetória escolar, como reprovações, abandono dos estudos; retorno ou permanência na escola; motivos para retorno aos estudos, entre outras informações.

\section{Resultados e discussão}

Com o intuito de caracterizar o perfil dos estudantes com deficiência matriculados na EJA nos municípios pesquisados, o Quadro 2 apresenta a, faixa etária, nível de ensino EJA, ocupação, carga horária de trabalho semanal, e demais informações a fim situá-los no contexto do estudo. Além disso, analisou-se a constituição familiar pelo nível de escolaridade dos pais e condições socioeconômicas, conforme apresentado no Quadro 2.

Quadro 2 - Participantes e constituição familiar segundo a escolaridade dos pais, condições socioeconômicas.

\begin{tabular}{|l|l|l|l|l|l|}
\hline Participante $^{1}$ & Idade & Série & Deficiência & $\begin{array}{l}\text { Estado } \\
\text { Civil }\end{array}$ & Ocupação \\
\hline Igor & 32 & $\begin{array}{l}2^{0} \\
\text { ano }\end{array}$ & Surdez & Casado & Ajudante de Produção \\
\hline Cleiton & 28 & $\begin{array}{l}2^{0} \\
\text { ano }\end{array}$ & $\begin{array}{l}\text { Deficiência } \\
\text { visual }\end{array}$ & $\begin{array}{l}\text { União } \\
\text { estável }\end{array}$ & $\begin{array}{l}\text { Beneficiário } \\
\text { Previdência Social }\end{array}$ \\
\hline
\end{tabular}

${ }^{1}$ Os nomes dos participantes são fictícios para preservar suas identidades. 
http://dx.doi.org/10.5902/1984686Xx27878

\begin{tabular}{|c|c|c|c|c|c|}
\hline Danilo & 19 & $\begin{array}{l}3^{\circ} \\
\text { ano }\end{array}$ & $\begin{array}{l}\text { Deficiência } \\
\text { física }\end{array}$ & Solteiro & Sem ocupação \\
\hline Wesley & 33 & $\begin{array}{l}2^{\circ} \\
\text { ano }\end{array}$ & Surdez & Casado & Ajudante de Produção \\
\hline Luan & 32 & $\begin{array}{l}2^{\circ} \\
\text { ano }\end{array}$ & $\begin{array}{l}\text { Deficiência } \\
\text { visual }\end{array}$ & Casado & Aposentado Invalidez \\
\hline Denis & 23 & $\begin{array}{l}3^{\circ} \\
\text { ano }\end{array}$ & $\begin{array}{l}\text { Deficiência } \\
\text { física }\end{array}$ & Solteiro & $\begin{array}{l}\text { Beneficiário da } \\
\text { Previdência Social }\end{array}$ \\
\hline Gustavo & 20 & $\begin{array}{l}3^{\circ} \\
\text { ano }\end{array}$ & $\begin{array}{l}\text { Deficiência } \\
\text { visual }\end{array}$ & Solteiro & Jardineiro \\
\hline José & 24 & $\begin{array}{l}3^{\circ} \\
\text { ano }\end{array}$ & $\begin{array}{l}\text { Deficiência } \\
\text { física }\end{array}$ & Solteiro & Sem ocupação \\
\hline Jean & 24 & $\begin{array}{l}3^{\circ} \\
\text { ano }\end{array}$ & $\begin{array}{l}\text { Deficiência } \\
\text { visual }\end{array}$ & Solteiro & $\begin{array}{l}\text { Beneficiário } \\
\text { Previdência Social }\end{array}$ \\
\hline Luciano & 19 & $\begin{array}{l}2^{\circ} \\
\text { ano }\end{array}$ & $\begin{array}{l}\text { Deficiência } \\
\text { intelectual }\end{array}$ & Solteiro & Estudante \\
\hline
\end{tabular}

Fonte: As autoras (2016).

Como pode ser averiguado no Quadro 2, todos os participantes são do sexo masculino, com idade entre 19 anos e 33 anos. A maioria dos participantes era solteiro (seis participantes), apenas três deles tinham filhos. Dentre os participantes, dois são surdos, quatro são deficientes visuais, três são deficientes físicos e um participante tem deficiência intelectual.

Lima e Silva (2015), em um estudo que caracterizou o perfil dos alunos da EJA de um município de pequeno porte do interior do Estado de São Paulo entre os anos de 2011 e 2013, identificou que, entre os estudantes com deficiência, há predominância de jovens, seguidos por adultos, e com idosos. No período pesquisado, o número de jovens com menos de 21 anos de idade correspondia a 51,61\%, em 2011, e 34,88\% em 2013.

Embora a caracterização dos participantes dessa pesquisa revele o perfil jovem do alunado como um traço marcante nesse espaço, a heterogeneidade do grupo também indica os desafios presentes no processo educacional, o que deve refletir sobre novas propostas que englobem as particularidades deste público, nos seus aspectos sociais, históricos e culturais, uma vez que o ingresso na EJA representa para esses estudantes a conclusão de uma escolarização até então não bem-sucedida. 
http://dx.doi.org/10.5902/1984686Xx27878

No entender de Hass (2013, p. 74), o perfil jovem do estudante da EJA pode ser explicado pela necessidade de que estejam em idade precoce para a incorporação no mercado de trabalho. Assim como a própria legislação brasileira estipulou a redução da idade para ingresso na modalidade, a LDBN no 9394/96 determinou a idade de ingresso de 15 anos para o ensino fundamental e de 18 anos para o ensino médio. Segundo a autora, atualmente "(...) o perfil cada vez mais jovem, também coloca em evidência o "fracasso" da escola regular, que depois de um histórico de sucessivas repetências do aluno, chegando por vezes à evasão escolar, estimula-o para ingressar na EJA".

No contexto nacional, de acordo com Haddad e Di Pierro (2000), até a década de 1980, o perfil da EJA era composto por pessoas mais velhas, geralmente da zona rural, que não haviam frequentado a escola por falta de oportunidades. A partir de 1980, os programas de escolarização de adultos passaram a incluir jovens de origem urbana que já haviam tido uma experiência escolar, porém sem sucesso.

O rejuvenescimento da população que frequenta a EJA tem sido alvo de estudos e atenção por parte dos educadores. Para Brunel (2004) o fenômeno da rejuvenilização na EJA iniciou-se na década de 1990, após o silenciamento ocorrido no período militar, período que começou a utilizar a terminologia educação de jovens e adultos. Muitos destes jovens vivenciaram a experiência de frustração no ensino básico. Além disso, a autora acrescenta que "fatores pedagógicos, políticos, legais e estruturais fazem com que muitos jovens procurem cada vez mais esta modalidade a cada ano mais precocemente". Muitos desses jovens chegam à escola desmotivados, sentindo-se culpados por um fracasso que não cabe somente à eles, mas ao professor, pois segundo a pesquisadora cumpre "(...) (re) significarmos o lugar 'simbólico' destes estudantes e superarmos o rótulo de fracassados que frequentemente a comunidade escolar os impõe, e retomar com eles sua posição de sujeitos no processo educativo" (BRUNEL, 2004, p. 21).

Entre os participantes do estudo, três declararam trabalhar formalmente (Wesley, Igor e Gustavo) com jornada de 40 horas semanais ou mais. Entre os demais participantes, quatro afirmaram receber benefícios da previdência social (Luciano, Cleiton, Denis, Jean e Luan), dois participantes informaram não ter nenhuma ocupação (Danilo e José) e apenas um deles mencionou dedicação exclusiva aos estudos (Luciano).

O fato de quatro participantes receberem benefícios da Previdência Social é um registro de que pessoas jovens não estão inseridas no mercado de trabalho. Os próprios participantes afirmaram que o motivo para a continuação dos estudos é a possibilidade de 
http://dx.doi.org/10.5902/1984686Xx27878

melhor qualificação para o futuro ingresso no mercado de trabalho. No entanto, a inserção da pessoa com deficiência no mercado de trabalho demanda ações que possibilitem essa inclusão. Nesse sentido, Antunes (2012) salienta que seria importante que as escolas preparassem esses alunos com deficiência para que atuem no contexto social como cidadãos autônomos e com capacidade para uma atividade profissional. Contudo, essa transição da escola para o trabalho é complexa, necessitando de programas educativos que trabalhem a formação profissional.

Tais dados corroboram com Fantacini e Campos (2017), ao indicarem que os estudantes com deficiência que frequentam a EJA atribuem à escolarização o desejo de aprender a ler e escrever, de avançar nos estudos e concluí-los, conseguir um emprego, tirar a carteira de habilitação, entre outros aspectos.

Sobre esse assunto, Santos (2011) afirma que muitas pessoas com deficiência não se inserem no mercado de trabalho mesmo com capacidade para o exercício de diversas funções, devido ao receio de perder o benefício que muitas vezes recebem da previdência social, em outras palavras por temer a perda do vínculo empregatício. Embora não seja essa a interpretação da lei, uma vez que o benefício pode ser requerido novamente, essas situações são recorrentes. O estudo realizado por Flogi (2010) discutiu a transição para a vida adulta das pessoas com deficiências e a formação profissional. A autora destaca que a educação profissional é tão importante para a autonomia do estudante que, embora tenha havido avanço das políticas inclusivas, ainda se faz necessário repensar mais detidamente todo o processo de formação profissional dos estudantes com deficiência. Quanto a isso, seria interessante que as escolas pudessem multiplicar as oportunidades voltadas ao desenvolvimento social, educativo e profissional dos estudantes.

Mesmo afirmados como princípios da EJA a qualificação para vida em cidadania e a capacitação para o mercado de trabalho, estas questões de formação nem sempre estão incluídas no cotidiano escolar, o que acaba por inibir e obstar a preparação desses estudantes para a formação profissional.

Em se tratando da atenção ao alunado atual da EJA, constatamos a pouca expressividade de políticas públicas que legislam sobre a modalidade sem considerar o perfil desses estudantes, o que repercute de forma negativa nas práticas pedagógicas adotadas no contexto escolar. Sendo assim, a EJA ainda apresenta um currículo tradicional, sem a interlocução com aspectos presentes no cotidiano dos estudantes, 
http://dx.doi.org/10.5902/1984686Xx27878

descontextualizado da realidade e com professores despreparados para lidar com as demandas atuais dos estudantes.

Quanto à caracterização familiar dos participantes, o total de residentes em média em cada casa era de três pessoas (Luciano, Jean, Gustavo, Denis e Wesley); três informaram residir em um núcleo familiar formado por duas pessoas (Igor, Luan e Cleiton); e dois deles declararam que o número de moradores na residência era superior a cinco pessoas (José e Danilo). Todos os participantes residem na zona urbana: cinco residiam em casas alugadas (Igor, Danilo, Jean, Luan e Denis); quatro moravam em casa própria (Wesley, Gustavo, José e Luciano) e um residia em moradia cedida (Cleiton).

No que concerne ao nível de escolaridade das mães, a análise dos dados indicou que apenas a mãe de um participante tinha o ensino superior completo (Igor), a predominância foi do ensino fundamental completo para as mães dos participantes (Cleiton, Danilo, Wesley, Luan, Denis, Gustavo, José e Jean); e a mãe do participante (Luciano) concluiu o ensino médio. Sobre a escolarização dos pais, apenas um participante afirmou que pai concluiu o nível de ensino superior (Wesley). Outro participante afirmou desconhecer a escolarização do pai (lgor), dois deles afirmaram que os pais tinham ensino médio completo (Danilo e José), e os outros seis informaram que os pais tinham o ensino fundamental completo (Cleiton, Luan, Denis, Gustavo, Jean e Luciano).

A análise da renda média familiar dos participantes, somando-se todos os ganhos dos moradores da residência, revelou que sete deles tem renda mensal média entre 1 a 3 salários mínimos (Igor, Cleiton, Danilo, Luan, Gustavo, Jean e Luciano). Um participante declarou renda de 1 salário mínimo (Wesley); outro afirmou ter renda familiar de 3 a 6 salários mínimos (Denis) e um deles mencionou renda entre 6 a 9 salários mínimos (José).

Sobre esse aspecto, estudos apontam que o perfil dos estudantes que frequentam a EJA, em geral, é próprio de classes econômicas mais desfavorecidas, com baixo nível de escolaridade dos pais. Na maior parte dos casos, esses estudantes precisam evadir-se da escola para dedicar ao trabalho e contribuir com a renda da família (KOHL, 1999; AJALA, 2011, FERREIRA, 2015).

Pensando nessas particularidades, Ferreira (2015) investigou quem são os sujeitos que entram na EJA precocemente e as sutilezas dos processos de hierarquização, segregação e reprodução de desigualdades de uma escola em Ouro Preto/MG. Entre os resultados, constatou o crescente número de jovens na EJA na cidade pesquisada, entre os motivos a autora mencionou a própria legislação que determina a certificação de 15 anos 
http://dx.doi.org/10.5902/1984686Xx27878

no Ensino Fundamental II, o que esclarece haver, após essa idade, mais matrículas incorporadas na EJA.

$\mathrm{Na}$ análise sobre a trajetória escolar, dois participantes relataram nunca ter repetido de ano (Gustavo e José); outros três afirmaram ter repetido uma vez (Igor, Cleiton e Denis); outro mencionou desistir da escola quando percebia que ia repetir (Luan); outro participante nunca tinha sido reprovado, mas ficou retido um ano a mais na educação infantil (Luciano), e três participantes declararam ter sido reprovados por mais de duas vezes (Danilo, Wesley e Jean).

As autoras Liduenha e Meletti (2009) encontraram resultados parecidos em um estudo que analisou as trajetórias escolares de estudantes oriundos da classe especial para a EJA - no percurso escolar dos estudantes havia um histórico de repetência nas séries comuns e a permanência de longos períodos nas classes especiais, trajetórias em que os estudantes ingressam na EJA sem perspectiva de término dos estudos.

Nesse sentido, Gonçalves (2012, p.31) argumenta que "a trajetória escolar de pessoas com necessidades especiais tem mostrado que o processo de ensino aprendizagem não tem sido efetivado no que concerne ao acesso, permanência e ensino". Portanto, garantir 0 acesso do estudante com deficiência no ensino regular sem assegurar a qualidade e a permanência de tais estudantes na escola não significa incluir. Embora o desafio seja complexo, é possível construir uma escola inclusiva para todos.

O nível de ensino no momento da interrupção ocorreu para a maioria dos participantes no ensino fundamental: um participante interrompeu os estudos na $4^{\underline{a}}$ série do ensino fundamental (José); e cinco interromperam os estudos na 8aㅗ série do ensino fundamental (Igor, Cleiton, Danilo, Denis e Jean). Cerca de três deles interromperam os estudos no $1^{\circ}$ ano do ensino médio antes da conclusão do período (Luan, Gustavo e Wesley), apenas um nunca interrompeu os estudos (Luciano). A idade no momento da interrupção foi entre 14 e 19 anos para oito participantes, ou seja, a interrupção ocorreu mais na faixa etária de jovens do que de adultos ou crianças.

Como se pode observar, a trajetória dos participantes coincide com a tendência do histórico escolar das pessoas com deficiências, no qual a permanência na escola tende a ser interrompida antes da conclusão do ensino fundamental. De fato, as trajetórias revelam que mesmo aqueles que conseguiram ingressar no ensino médio não conseguiram concluir o ciclo, direcionando-se, posteriormente, para a EJA. 
http://dx.doi.org/10.5902/1984686Xx27878

Entre os motivos de interrupção dos estudos revelados pelos participantes, três apontaram a necessidade de trabalhar (Igor, Gustavo e Luan). A mudança inesperada de vida foi apontada por dois participantes (José e Denis); motivos de ordem pessoal, como desânimo, foram indicados por outros dois (Jean e Cleiton); dificuldades pedagógicas foram citadas por um participante (Wesley); assédio moral por outro (Danilo); e um deles nunca interrompeu os estudos (Luciano).

\begin{abstract}
Eu estudava na parte de manhã, eu não tava trabalhando, depois quando eu comecei a trabalhar aí se sabe. [...] Por causa do trabalho...parei (Gustavo).
\end{abstract}

Parei de estudar, não porque eu quis, é porque nós somos três deficientes, é eu e duas meninas, a L. que é a caçula ela ficou internada e aí a mãe não teve como levar nós dois na escola, teve que parar. (José)

Quando eu tinha 18 anos eu sofri um acidente[...]daí não deu para voltar mesmo[...] tive que ficar 3 anos em recuperação, muito corpo tava muito fraco, dava muita febre, as vezes tava bom, as vezes não tava, eu tive que adaptar de novo, não conseguia agora ficar das 7 horas até as 11 horas sentado tranquilo, chegar em casa sem dores, sem nada. (Denis)

Na escola eu parei de estudar, por que eu não aguentava as brincadeiras. [...] uma vez eu fiquei 6 meses, depois a minha mãe quis que eu voltasse eu tentei fiquei 8 meses e não aguentei. (Danilo)

Dados a respeito do tempo de permanência fora da escola apontaram que seis participantes, a maioria, ficaram afastados entre oito e dez anos até retornarem aos estudos (Cleiton, Wesley, José, Jean, Luan e Igor). Os participantes (Danilo, Denis e Gustavo) ficaram longes do ambiente escolar de um a cinco anos. Quanto à idade de retorno aos estudos, sete dos participantes, a maioria, voltaram a estudar com a idade entre 19 e 29 anos de idade (Denis, Gustavo, José, Jean, Danilo, Cleiton e Igor). Apenas os participantes (Wesley e Luan) retornaram para a escola com mais de 30 anos. Entre os motivos para voltarem a estudar, quatro participantes afirmaram o desejo de conseguir um emprego (Cleiton, Danilo, Denis e Jean); três desejavam adquirir mais conhecimentos e ficarem atualizados (Igor, José e Luan); dois disseram que retornaram à escola para atender às expectativas da família em relação aos estudos (Wesley e Gustavo); e um participante nunca interrompeu os estudos (Luciano).

Com isso podemos entender que todos os participantes atribuem à escola um aspecto importante, no sentido de que ela pode contribuir para o seu progresso tanto no presente como no futuro, ou seja, reconhecem que a escola pode ser o caminho de concretização de seus projetos de vida. 
http://dx.doi.org/10.5902/1984686Xx27878

A escola tem um papel importante na vida de todas as pessoas, e a EJA incorpora essa responsabilidade nos seus princípios norteadores, ela ocupa função essencial na vida dos estudantes ao Ihes oferecer oportunidades educacionais adequadas, que contempla suas características individuais, e ainda lhes proporciona conhecimentos e habilidades necessárias para o exercício da cidadania.

Por outro lado, há o reconhecimento pelos estudantes de que a escola está correspondendo às suas expectativas, pois, além de oferecer a alfabetização, outros elementos importantes, como exercitar o convívio e vivenciar a cidadania, também são experimentados, ou seja, a educação passa a ser vista em toda a sua amplitude social. No entanto, Cleiton, contrariamente, destaca não ter muita expectativa de que a escola e EJA poderá auxiliar no seu aprendizado, para ele a escola é tida como um passatempo e a deficiência representa um forte obstáculo, ele não vê alternativas na escola que possam ajudá-lo a superar tal condição.

\footnotetext{
Eu gosto (refere-se à escola) por que pelo menos eu distraio mais. [...] eu acho que o único obstáculo mesmo seria meu problema. [...] eu acho que não viu, não tem o que me ajudar, acho que a escola não tem o que me ajudar, só se for me ajudar na sala de aula, igual os professores estão me ajudando, os alunos me ajuda, mas de outra forma não. (Cleiton)
}

A narrativa expressada por Cleiton demonstra o sentimento do participante pela escola como distração; por outro lado, acredita que a escola não poderá oferecer condições para superar sua deficiência. O fato de o estudante estar no início da vida adulta e já manifestar um sentimento pessimista quanto a poder exercer atividades futuras provavelmente está relacionado à cultura social que julga o deficiente como incapaz ou que ele, diante de sua condição, não poderá exercer atividades com independência.

Pode-se afirmar, portanto, que, quando a escola assume um papel ativo, deixando que os estudantes sejam protagonistas de suas capacidades, eles entenderão que a deficiência não é impedimento para alcançarem a autonomia. Isso requer que as escolas compensem as necessidades dos estudantes com práticas educativas inclusivas que permitam a todos o desenvolvimento de suas potencialidades.

\section{Considerações finais}

A EJA ao longo do tempo foi constituída e direcionada para aqueles que por motivos diversos não tiveram como concluir a escolarização. No entanto, ganhou força nas últimas décadas a incorporação de um novo perfil de alunado na modalidade, com destaque para 
a juvenilização do seu público. É válido acrescentar que, atualmente, para muitos destes alunos não são negadas oportunidades de acesso à escola; contudo, fatores diversos ligados ao ambiente escolar acabam por excluir esse aluno da escola, contribuindo assim para trajetórias escolares fragmentadas, como constatado no estudo.

A partir do presente estudo, notou-se que o perfil dos estudantes da pesquisa que frequentavam a EJA era predominantemente masculino e jovem. Verificou-se também que este alunado interrompeu os estudos por motivos diversos, a grande maioria antes de concluir o ensino fundamental.

Assim é possível concluir que apesar da escolarização fragmentada, o estudante da EJA com deficiência reconhece que a escola representa a oportunidade de ascensão profissional, o espaço certo para romper com o processo de fragmentação.

Neste sentido, evidencia-se a relevância deste estudo, porque nele se buscou conhecer o perfil dos estudantes que frequentam a EJA como forma de compreender quem são esses indivíduos e como é sua trajetória escolar, para então planejar e promover o desenvolvimento educacional a que têm direito no contexto do ensino regular.

\section{Referências}

AJALA, Michelle Cristina. Aluno EJA: motivos de abandono e retorno escolar na modalidade EJA e expectativas pós EJA em Santa Helena - PR. 2011. 44 p. Monografia (Especialização) - Universidade Tecnológica Federal do Paraná. Disponível em:< http://repositorio.roca.utfpr.edu.br/jspui/bitstream/1/1647/1/MD_PROEJA_2012_IV_16.pdf >. Acesso em: 20 mar. 2016.

ANTUNES, KATIUSCIA, C. História de Vida de alunos com deficiência intelectual: percurso escolar e a constituição do sujeito. 2012. 154 p.. Tese (Doutorado) - Faculdade de Educação, Universidade do Estado do Rio de Janeiro, Rio de Janeiro, 2012. Disponível em:

uerj.pro.br/images/pdf/KatiusciaAntunes_Tese_2012.pdf >. Acesso em: 10 fev. 2016.

BRASIL. Lei no 9.394, de 20 de dezembro de 1996. Estabelece as diretrizes e bases da educação nacional.

BRASIL. Ministério da Educação e Cultura (MEC). Secretaria da Educação Especial. Política Nacional de Educação Especial, na perspectiva da Educação Inclusiva. Brasília: MEC/SEESP, 2008. Disponível em: < http://portal.mec.gov.br/index.php?option=com_docman\&view=download\&alias=16690politica-nacional-de-educacao-especial-na-perspectiva-da-educacao-inclusiva$05122014 \&$ Itemid=30192 >. Acesso em: 01 mar. 2016. 
BRASIL. Ministério da Educação e Cultura (MEC). Resolução SE 3, de 13-1-2010: Dispõe sobre alterações na organização dos cursos de Educação de Jovens e Adultos, mantidos pelas escolas estaduais. Brasília, 2010. Disponível em: < http://siau.edunet.sp.gov.br/ltemLise/arquivos/03_10.HTM?Time=26/01/2016\%2014:10:28 >. Acesso em: 29 mar. 2016.

BRUNEL, Carmem. Jovens cada vez mais jovens na educação de jovens e adultos. $3^{a}$ ed. Porto Alegre: Mediação, 2004. 144p.

FANTACINI, Renata. A.F. CAMPOS, JulianaAparecida P. P. Conclusão da escolaridade de alunos com deficiência intelectual matriculados na educação de jovens e adultos / Education completion of students with intellectual disabilities attending youth and adult education.Revista de Educação PUC-Campinas, [S.I.], v. 22, n. 2, p. 317-330, jun. 2017. ISSN 2318-0870. Disponível em: <http://periodicos.puccampinas.edu.br/seer/index.php/reveducacao/article/view/3610>. Acesso em: 06 nov. 2018. doi:<https://doi.org/10.24220/2318-0870v22n2a3610>.

FERREIRA, Lorence D.M. Juvenilização na educação de jovens e adultos de Ouro Preto/MG: trajetórias e perspectivas dos estudantes mais jovens. 2015. 122 p.. Dissertação (Mestrado em Educação) - Programa de Pós-Graduação da Universidade Federal de Ouro Preto. Mariana, Minas Gerais. Disponível em: < http://www.repositorio.ufop.br/bitstream/123456789/5428/1/DISSERTA\%C3\%87\%C3\%83 O_Juveniliza\%C3\%A7\%C3\%A3oEduca\%C3\%A7\%C3\%A3oJovens.pdf >. Acesso em: 15 out. 2015.

GONÇALVES, Taísa GrasielaG.L. Escolarização de alunos com deficiência da educação de jovens e adultos: uma análise dos indicadores educacionais brasileiros. 2012. 75 f. Dissertação (Mestrado em educação) - Universidade Estadual de Londrina, Londrina, $2012 . \quad$ Disponível em: <http://www.uel.br/pos/mestredu/images/stories/downloads/dissertacoes/2012/> Acesso em: 27 ag. 2016.

HAAS, Clarissa. Narrativas e percursos escolares de jovens e adultos com deficiência: "isso me lembra uma história!". 2013. 214 f. Dissertação (Mestrado em educação) - Universidade Federal do Rio Grande do Sul, Porto Alegre, 2013.

HAAS, Clarissa. Educação de jovens e adultos e educação especial: a (re)invenção da articulação necessária entre as áreas. Revista Educação. Santa Maria, v. 40, n. 2, p. 347360, maio/ago. 2015.2 Disponível em: < http://periodicos.ufsm.br/reveducacao/article/view/9038/0 >. Acesso em: 01 mar. 2016.

HADDAD, Sérgio; DI PIERRO, MariaClara. Aprendizagem de jovens e adultos: avaliação da década da educação para todos. São Paulo em Perspectiva. São Paulo, v. 14, n. 1, p. 29-40, mar. 2000.2 Disponível em: $<$ http://www.scielo.br/scielo.php?script=sci_arttext\&pid=S010288392000000100005\&Ing=en\&nrm=iso>. Acesso em: 01 mar. 2015. 
http://dx.doi.org/10.5902/1984686Xx27878

HADDAD, S.; DI PIERRO, M.C Transformações nas políticas de Educação de Jovens e Adultos no Brasil no início do terceiro milênio: uma análise das agendas nacional e internacional. Caderno Cedes, Campinas, v. 35, n. 96, p. 197-217, maio-ago., 2015.

IBGE. Pesquisa Nacional por Amostra de Domicílio, 2012. Rio de Janeiro, IBGE, 2013

KHOL, Marta. Jovens e adultos como sujeitos de conhecimento e aprendizagem. Revista Brasileira de Educação. n.12, p. 59-73, set/out/nov/dez, 1999.

LAPLANE, Adriana Lia F. Condições para o ingresso e permanência de alunos com deficiência na escola. Caderno CEDES, Campinas, v. 34, n. 93, p. 191-205, mai. 2014. Disponível em: <http://www.scielo.br/scielo.php?script=sci_arttext\&pid=S0101$32622014000200191 \&$ Ing=en\&nrm=iso $>$. Acesso em: 19 de mar. 2016.

LIDUENHA, Taísa Grasiela. G.; MELETTI, Silvia. Marta. F. Percurso escolar de alunos de Educação de Jovens e Adultos egressos de classe especial. In: ENCONTRO ANUAL DE INICIAÇÃO CIENTÍFICA - EAIC, 2009, Londrina. XVIII Encontro Anual de Iniciação Científica, 2009. CD- ROM.

LIMA, Fabiana O.; SILVA, Nilson Rogério. Educação inclusiva de jovens e adultos em um município do interior de São Paulo. Revista Cadernos de Educação. n.5 2, p.1-21, 2015. Disponível em: <https://periodicos.ufpel.edu.br/ojs2/index.php/caduc/article/viewFile/7312/5120>. Acesso em: 01 fev. 2016.

MELETTI, Silvia Marta. F. A inclusão de alunos com necessidades educacionais especiais no sistema regular de ensino no município de Londrina. In: $32^{a}$ REUNIÃO ANUAL DA ANPED: SOCIEDADE, CULTURA E EDUCAÇÃO: NOVAS REGULAÇÕES. Caxambu. 2009. p. 01-12.

MOREIRA, Laura C.; CARVALHO, Ana Paula. de. (Des)continuidade nos estudos de alunos com deficiência na trajetória do Ensino Fundamental ao Médio: uma análise inicial dos microdados MEC/INEP. Revista Educação Especial, Santa Maria, p. 283-298, jun. 2014. Disponível em: <http://periodicos.ufsm.br/educacaoespecial/article/view/9132>. Acesso em: 30 jan. 2017.

SANTOS, Wenderson R. Deficiência e BPC: o que muda na vida das pessoas atendidas? Revista Ciência e Saúde coletiva. v. 16, supl. 1. P. 787 - 796, 2011.

\section{Correspondência}

Graciliana Garcia Leite - Universidade Federal de São Carlos (UFSCar), Rodovia Washington Luís, s/n, CEP: 13565-905. São Carlos, São Paulo, Brasil.

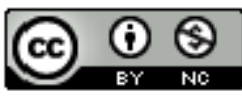

This work is licensed under a Creative Commons Attribution-NonCommercial 4.0 International (CC BY-NC 4.0) 